\title{
REFUGIO Y ASILO DE BOLIVIANOS DURANTE LA DICTADURA CHILENA ENTRE 1973 Y 1975*
}

\author{
REFUGE AND ASYLUM OF BOLIVIANS DURING THE CHILEAN \\ DICTATORSHIP. 1973 AND 1975
}

\author{
Adriana Palomera ${ }^{* *}$ y Carmen Norambuena**
}

\begin{abstract}
Partimos de la hipótesis de que Chile en la década de los años setenta tuvo dos escenarios diferentes. En los inicios se configuró como un país confiable al que se podría emigrar, exiliarse o solicitar refugio con la certeza de que, debido a las características del régimen socialista, este podía albergar a todos aquellos que se sintieran amenazados en sus países de origen. Luego del golpe militar de 1973, el panorama político-social del país cambió. Bajo estas condiciones, se produjeron movimientos de personas asociadas a situaciones de asilo, exilio y refugio, razón por la que es preciso discurrir acerca de su diferencia conceptual.

Este artículo trata específicamente del refugio y asilo de bolivianos en Chile entre el gobierno del presidente Salvador Allende y los inicios de la dictadura militar.

A causa de que la protección de refugiados se convirtió en una problemática regional, demandó la intervención de organismos internacionales como el Alto Comisionado de las Naciones Unidas para los Refugiados (ACNUR); el Comité Intergubernamental para las Migraciones Europeas (CIME), el Comité Nacional para Ayuda a los Refugiados (CONAR), y la Organización de las Naciones Unidas (ONU).

La metodología utilizada se basa fundamentalmente en el análisis de información documental, como los salvoconductos emitidos por el Ministerio de Relaciones Exteriores de Chile, que permiten evidenciar un proceso que, en este escrito, denominaremos "doble refugio".
\end{abstract}

Palabras claves: Chile, Bolivia, asilo, refugio.

Our hypothesis is that Chile in the 1970's presented two different scenarios. At first, it appeared as a reliable country, where one could migrate, go into exile or seek refuge, trusting that the socialist government could receive anyone who felt threatened in their home countries. After the 1973 military coup, the country's socio-political conditions varied, whereupon people began to move out seeking political asylum or directly into exile. Under such circumstances, it is necessary to delve into the conceptual difference between one situation and another.

This article deals specifically with the experience of political refuge and asylum of Bolivian nationals in Chile during the presidency of Salvador Allende and the early years of military dictatorship.

Because refugee protection became a continent-wide problem, the involvement of international agencies such as the United Nations High Commissioner for Refugees, the Inter-Governmental Committee for European Migrations, the National Committee for Refugee Aid and the United Nations, became mandatory.

The methodology applied is fundamentally based on documentary evidence, such as safe-conducts issued by Chile's Ministry of Foreign Relations, which demonstrate a process that in this paper is defined as a "double refuge".

Key words: Chile, Bolivia, asylum, refuge.

\section{Introducción}

Es reconocido el papel que en distintos períodos jugaron los países latinoamericanos en el otorgamiento de asilo y refugio de quienes lo requirieron. Lo propio ocurrió en Chile, país que destaca por su historia de recepción y acogida de asilados y refugiados desde el siglo decimonónico hasta el presente. Así como aconteció en los primeros tiempos republicanos, al amparo de una política de asilo, se dio protección a ciudadanos de otras repúblicas latinoamericanas que por diversos motivos debieron abandonar su país como lo fueron, entre otros, los argentinos Domingo Faustino Sarmiento y Juan Bautista Alberdi, que escaparon de la dictadura de Juan Manuel de Rosas. O más tarde en el siglo $\mathrm{XX}$ cuando el país recibe a los judíos que huyen de la persecución nazi en Europa (Brahm y Montes

\footnotetext{
* Resultado proyecto Desempeño USA 1498, Centro de Estudios Migratorios de la Universidad de Santiago de Chile. CEM-USACH.

** Universidad de Santiago de Chile, Chile. Correo electrónico: apalomera37@gmail.com; carmen.norambuena@usach.cl
} 
2012), como también a los republicanos españoles al término de la guerra civil (Norambuena 2008) y, al correr el siglo, a los expulsados de las dictaduras latinoamericanas.

Esta política histórica de recepción contribuye a explicar que en Chile a inicios de la década de 1970 se encontraran ciudadanos de varios países latinoamericanos procedentes de Argentina, Bolivia, Brasil, Nicaragua, Guatemala y Cuba; y también, otros procedentes de España, Alemania, y de la Unión Soviética (Garcés y Nicholls 2005).

Para América Latina, el refugio, en su dimensión reglamentaria y legislativa, se hizo visible con la seguidilla de golpes de Estado que, inspirados en la Doctrina de Seguridad Nacional, como fue el caso de Bolivia, o en militarismos nacionalistas como fue en Perú (Del Pozo 2009), instalaron gobiernos castrenses que significaron desplazamientos de personas en calidad de asilados o refugiados. Así fue como en "el decenio de 1960 el papel de los militares adquirió un tono internacional, en el marco de la hegemonía de Estados Unidos y bajo el efecto de la guerra fría" (De la Peña 1997: 284). Mientras unos países expulsaron población otros se convirtieron en lugares de refugio y amparo.

Nos ha parecido relevante hacer una diferencia conceptual respecto de la emigración, el exilio, el asilo y el refugio (Sznajder y Roniger 2013).

En primer lugar, como lo hemos señalado en otros escritos, la diferencia fundamental entre la emigración y el exilio es el carácter de obligatoriedad de este último, pues las personas son conminadas a abandonar su país de residencia por tiempo indefinido. La voluntad del gobernante autoritario es la expulsión y el impedimento de que las personas continúen con el desarrollo normal de sus proyectos de vida (Norambuena 2000).

Este carácter coercitivo diferencia el exilio de la migración, puesto que, quien opta por el exilio no tiene opción, debe partir, en tanto que el migrante parte por voluntad propia, aunque en su decisión se hayan conjugado razones imperiosas en la necesidad de salir del territorio o país natal. Estos pueden regresar a su país cuando lo decidan conforme con la evaluación previa de las circunstancias políticas o las condiciones económicas de un momento determinado. En cambio "el exilio es siempre destierro, uno de los castigos más antiguos: el que manda o gobierna, expulsa, aleja y relega a una persona del país, de la patria en que nació y creció" (Norambuena 2000: 174).
De otra parte, en virtud del tema en estudio, es necesario establecer las diferencias entre asilo y refugio. En el primer caso, quienes solicitan esa condición son personas que buscan protección en legaciones diplomáticas de un país o lugares que se consideren como parte de la extensión del territorio nacional: consulados y residencias diplomáticas. Medios de transporte como buques o aviones de un determinado país, también son considerados parte de la soberanía territorial. Es ese el asilo diplomático. Por su parte, nuestro tema central, el refugio, se acepta como tal lo dispuesto por la Convención de Ginebra de 1951 y el protocolo de 1967 en que se expresa que un refugiado es una persona que busca amparo en un país distinto al propio debido a temores de ser perseguido por condición de raza, religión u origen natal (Convención de Ginebra, 1951; protocolo, 1967).

En el contexto de las dictaduras en América Latina y de los exilios políticos en el Cono Sur, Ayala y Mazzei sostienen que existió varias características similares en estos procesos que traspasaron las realidades nacionales como fue la coordinación de la represión (Operación Cóndor), que excedió la normativa interna; junto con esa particularidad, también se encuentra el aumento de la "militancia político-humanitaria y el desplazamiento forzado fuera del territorio nacional de miles de personas que vivieron diversos itinerarios de destierro. Las asociaciones represivas, exilios y experiencias de militancias políticas o humanitarias formaron una trama de procesos" (Ayala y Mazzei 2015: 6).

Este artículo explora el caso de los ciudadanos bolivianos que luego del golpe militar de Hugo Bánzer se dirigieron a Chile en busca de protección y que, acogidos inicialmente por el gobierno de Salvador Allende (1970-1973), debieron partir a un nuevo refugio para evitar caer bajo la represión dirigida en su contra durante los primeros años de la dictadura militar chilena, especialmente cuando muchos de ellos habían declarado su adhesión al proyecto socialista de la Unidad Popular.

Para el gobierno militar este grupo de latinoamericanos avecindados por razones políticas en Chile, se convirtió en un problema que había que solucionar lo más pronto posible, manifestando una "acentuada xenofobia hacia los refugiados de distintos países latinoamericanos, y extranjeros que simplemente habían llegado a Chile atraídos por la experiencia de la Unidad Popular" (Garcés y Nicholls 2005: 20). 
Se calcula que de los 13.000 extranjeros oficialmente reconocidos residentes en el país en 1973, alrededor de 5.000 eran latinoamericanos y que permanecían en Chile en calidad de refugiados, debiendo ser reubicados en otros países que les brindaran acogida (Garcés y Nicholls 2005: 21).

La metodología de investigación aborda los contextos históricos y políticos del periodo, señalando las etapas que recorre el problema y presentando algunos casos que ejemplifican la dinámica estudiada. A nivel de fuentes se trabajó con salvoconductos propiciados por el Ministerio de Relaciones Exteriores de Chile, compromisos y protocolos de organismos internacionales, así como documentos y resoluciones específicas de la materia. Este escrito identifica el número y condición de amparo de los ciudadanos bolivianos que obtuvieron la calidad de refugiados y asilados, así como parte de sus trayectorias. De igual forma, evidencia la importancia de organismos nacionales e internacionales involucrados en la protección de los refugiados en el contexto de la dictadura militar. El análisis cualitativo de fuentes y la elaboración e interpretación de datos fue realizada fundamentalmente conforme con la información de los salvoconductos emanados del Ministerio de Relaciones Exteriores de Chile entre 1973 y 1975. Este panorama fue complementado con información proveniente de organismos internacionales como ACNUR, CIME (en la actualidad Organización Internacional para las Migraciones OIM) e Informes de la Comisión Interamericana de Derechos Humanos sobre Chile 1974 (CIDH); junto con el Comité Nacional para Ayuda a los Refugiados CONAR creado en octubre de 1973, bajo el Decreto No 1308 del Gobierno de Chile.

\section{El preludio de la crisis boliviana}

En el acontecer histórico de Bolivia los tiempos que corren desde la década de los años 30 en adelante, la conducción del país estuvo en manos de una élite de carácter oligárquica y autoritaria con notoria influencia militar y de agudo conflicto en su interior. Otro rasgo de gran significación en esta sociedad altamente estratificada fue la exclusión política de la gran mayoría campesina e indígena, debido a su condición de no hablar ni escribir español y, además, de no poseer bienes raíces y solo precarios medios de subsistencia.

El desafío de vigorizar el Estado Nacional frente a las amenazas que significaba el fortalecimiento de los países vecinos, hizo que el país entrara en un tiempo de mejoras sociales y cambios económicos cifrados principalmente en la fundación de los Yacimientos Petrolíferos Fiscales Bolivianos (YPFB) que se constituyó en el organismo estatal para la explotación de los hidrocarburos, luego de la nacionalización de la Standar Oil (López 2013).

Entre aciertos y tropiezos los grupos polarizados representados por la oligarquía minero-feudal versus los nacionalistas revolucionarios, civiles y militares decantó finalmente en la Revolución de 1952. Esta sublevación constituyó un antes y un después en la historia de este país. "La toma del poder por parte del Movimiento Nacional Revolucionario (MNR) de Víctor Paz Estenssoro y Hernán Siles Suazo significó la primera revolución por insurrección popular con protagonismo obrero en América Latina" (López 2013: 201). Tal revolución que, pese a los cambios introducidos y logros alcanzados, no pudo consolidarse siendo violentamente interrumpida por el golpe militar de 1964.

Efectivamente, a partir de ese año de 1964, con el general René Barrientos se dio inicio a un extenso periodo de dictaduras militares en el país. En este tiempo los militares lograron acentuar e instaurar "el modelo de capitalismo de Estado, implementaron diversas estrategias de desarrollo que mantuvieron el enfoque de la sustitución de importaciones y fomentaron las inversiones de capital nacional y extranjero" (Péres 2003: 16).

Al propio tiempo se dio inicio a una gran represión y control de las organizaciones campesinas y sindicatos de mineros, produciéndose ejecuciones de consideración. Los sindicatos fueron abolidos, sus líderes fueron apresados y deportados, los sueldos "racionalizados" a la baja. Los militares ocuparon todos los puestos de relevancia. En su gobierno se capturó y mató al Che Guevara. Barrientos logró consolidarse con un estilo personalista y un aparato paramilitar con el que gobernó hasta 1968, en que muere en un accidente aéreo. Le sucedió el general Alfredo Ovando (1969-1970) y luego Juan José Torres (1970-1971). Al decir del historiador boliviano Fernando Cajías de la Vega, valorado recién después de su derrocamiento y posterior asesinato, "Torres se autodefinió como un militar revolucionario [...] pero su discurso no coincidía con la revolución socialista que pregonaba la Asamblea Popular, que tomó el poder legislativo desde el 22 de junio de 1971" (Cajías 2013: 172). 
Durante el gobierno del general Juan José Torres se evidenciaba un bajo respaldo entre los militares, logrando la aprobación de la izquierda al expulsar al Peace Corps, nacionalizando las minas de zinc Mathilde y subiendo los salarios de los mineros (Angell 1997: 111). Fue un período marcado por diversas iniciativas que se abocaron a colaborar con "los partidos y los sindicatos marxistas en la creación de una asamblea popular: los militares no quisieron aceptar su sistema de 'poder dual' y fue derrocado en agosto de 1971" (Angell 1997: 111). La destitución de Torres dio inicio a dictaduras aún más cruentas: "su gobierno, apoyado en la Central Obrera Boliviana, fue derrocado por grupos proestadounidenses al mando del general Hugo Bánzer el 21 de agosto de 1971" (Paredes 2004: 139; López 2013: 203).

Efectivamente, este golpe de Estado marcó el ascenso del general Hugo Bánzer Suárez al gobierno de Bolivia, quien mantuvo el poder durante siete años. Su llegada marca el inicio de la etapa dictatorial en el Cono Sur de América, abriendo el ciclo de "golpes contrarrevolucionarios de esa década. Le siguieron en junio y septiembre de 1973 los ejecutados en Uruguay y Chile, y en 1976, el encabezado por Videla y la Junta Militar en Argentina" (Hernández 2015).

Desde los primeros meses del nuevo gobierno hubo un gran número de presos políticos y de exiliados. La violencia volvió a apoderarse del país. No hubo respeto por la Constitución ni por las leyes y los cuerpos represivos se adueñaron del país. Entre 1971 y 1972 las universidades fueron cerradas. "Uno de los hechos más espantosos fue el fusilamiento de varios estudiantes en la universidad cruceña en agosto de 1971. Se produjeron también algunos casos de desaparecidos, no esclarecidos nunca, al estilo de la terrible dictadura argentina" (Mesa 2003: 702).

Acciones de violencia, secuestro y asesinato de personajes del mundo político detonaron el exilio del país de un número importante de personas no adictas al gobierno de Bánzer. Muchos de estos hechos fueron atribuidos a la acción coordinada de la "Operación Cóndor" que vinculó estrechamente a las dictaduras del cono sur de Bolivia, Chile, Argentina y Uruguay, en la lucha contra grupos insurgentes o contrarios a los gobiernos de corte militar (Mesa 2003: 709).

Estos acontecimientos acaecidos y prolongados en el tiempo en el país altiplánico indujeron a que ciudadanos bolivianos debieran abandonar su país, muchos de ellos por temor a ser perseguidos por pertenencia a determinados partidos políticos o por adherir a determinada tendencia ideológica. Organismos de derechos humanos señalan que "unos 19.000 debieron exiliarse. Se prohibió la actividad política y sindical, se censuró la prensa y se clausuraron emisoras de radio opositoras" (Mesa 2003: 709).

Durante este periodo los bolivianos que llegaron a Chile lo hicieron en busca de protección, solicitando condiciones de refugio en el país receptor. En muchos casos tanto "los asilados como quienes fueron sus colaboradores debieron actuar de forma sigilosa y a veces clandestina para eludir la normativa establecida por el gobierno militar" (Victoriano 2013: 21).

\section{Refugiados en Chile. Del asilo y protección a un doble refugio}

Al observar el refugio en Chile, consideramos necesario reconocer el marco legal en que se inscribió, sus características numéricas mediante algunos testimonios examinar parte de las circunstancias en que se desenvolvió.

Para el caso chileno, el refugio adquiere valor desde el momento en que grupos de exiliados de otras naciones latinoamericanas lo solicitaron. $\mathrm{La}$ expulsión de ciudadanos fue uno de los dispositivos utilizados por los gobiernos autoritarios que se habían instalado previamente en la región y que luego de los sucesivos golpes, incluyendo el de Chile, continuó siendo aplicada con rigor. "El exilio político era, entonces, uno de varios métodos utilizados sistemáticamente por el aparato represivo estatal para deshacerse de 'desviantes políticos' mediante el destierro, o bien, la única opción viable para los militantes políticos si querían salvarse" (Grinsvall 2012: 174).

En esta perspectiva, distinguimos para Chile dos etapas de refugio que se desarrollan entre 1970 y los primeros años de la dictadura militar de Augusto Pinochet. La primera entre 1970 y 1973; en tanto que la segunda va desde el golpe militar de 1973 hasta 1975.

La primera etapa se caracterizó por la recepción de refugiados latinoamericanos. En este periodo, la violenta dictadura de Hugo Bánzer y consiguiente salida masiva de ciudadanos bolivianos escapando o siendo expulsados por el régimen dictatorial, influyó 
en que el presidente Salvador Allende ratificara el Convenio de 1951, que en su artículo $\mathrm{N}^{\circ} 2$ reconocía como refugiados a las personas que:

debido a fundados temores de ser perseguida por motivos de raza, religión, nacionalidad, pertenencia a determinado grupo social $\mathrm{u}$ opiniones políticas, se encuentre fuera del país de su nacionalidad y no pueda o, a causa de dichos temores, no quiera acogerse a la protección de tal país; o que, careciendo de nacionalidad y hallándose, a consecuencia de tales acontecimientos, fuera del país donde antes tuviera su residencia habitual, no pueda o, a causa de dichos temores, no quiera regresar a él (ONU 1951).

Asimismo, que el ejecutivo ratificara el Protocolo de 1967 que complementaba el Convenio anterior, ya que aquel solo aplicaba a los que tenían la condición de refugiados antes de enero de 1951, en consideración a:

que han surgido nuevas situaciones de refugiados desde que la Convención fue adoptada y que hay la posibilidad, por consiguiente, de que los refugiados interesados no queden comprendidos en el ámbito de la Convención, considerando conveniente que gocen de igual estatuto todos los refugiados comprendidos en la definición de la Convención, independientemente de la fecha límite de $1 .^{\circ}$ de enero de 1951 (ONU 1967).

Además, este Protocolo ampliaba la protección de los refugiados a todos los ciudadanos del planeta, como señalamos, sin importar la fecha en que se produjera el desplazamiento (Wilkinson 2001). Hasta hoy, esta Convención sobre el Estatuto de los Refugiados de 1951, al igual que el Protocolo sobre el Estatuto de los Refugiados de 1967, se encuentran entre los principales documentos jurídicos de protección a refugiados, convirtiéndose en instrumentos que permiten ayudar a los que solicitan protección. Posteriormente, respondiendo al contexto latinoamericano, Chile suscribiría en 1984 la Declaración de Cartagena, que proponía se considerara como refugiados a los que habían salido de su país porque peligraba su vida, seguridad o libertad frente al contexto de las dictaduras de América Latina. Mucho más tarde, en el 2010, el gobierno de Chile publicaría la Ley $\mathrm{N}^{\circ} 20.430$, referida a "Disposiciones sobre Protección de Refugiados", que, en un nuevo contexto, regula tal condición.

Para el presidente Salvador Allende no habría sido la anterior dictadura de Brasil de 1964 la que habría provocado el refugio de un grupo de sus ciudadanos en Chile, ni la presencia de Velazco Alvarado en Perú la que generó la firma de estos convenios, sino que la experiencia boliviana. Esta ratificación coincidió con la llegada a Chile de un grupo de refugiados bolivianos en 1971, obligándolo a recurrir a organismos internacionales para que colaboraran en este proceso. Por ese entonces, el presidente de Chile, Salvador Allende, solicitó de manera inmediata la actuación de ACNUR frente a la situación de los refugiados bolivianos en Chile (ACNUR 2005: 94). Como estaba señalado en la Convención de 1951, era el Alto Comisionado de las Naciones Unidas para los Refugiados el que tenía por misión "velar por la aplicación de las convenciones internacionales que aseguran la protección a los refugiados" (ONU 1951). Según Jaime Esponda, esta organización tenía la responsabilidad de establecer ciertos protocolos para el trabajo y reconocimiento de los que necesitaban protección (Esponda 2004).

La firma de estos acuerdos marcó un corte entre un antes y un después en materia jurídica, y fueron los fundamentos que permitieron la protección de los refugiados en el contexto de la dictadura chilena, constriñendo a dicho gobierno a dar protección a estos demandantes.

Especificamente, ACNUR prestó especial atención al proceso chileno, preocupándose de promover servicios de asistencia y convirtiéndose en un programa sustancial que coordinó y coordina las distintas operaciones de ayuda. De este modo, ACNUR procura cubrir necesidades básicas como la alimentación, atención médica, entre otras (Melander 1981).

Destaca como característica del período del presidente Salvador Allende ser percibido por muchos intelectuales, políticos y militantes de Latinoamérica como un proceso en que la experiencia socialista era factible, motivando la llegada al país tanto de simpatizantes del modelo económico y político de la Unidad Popular pero también como lugar de protección y asilo; tal fue el caso de los brasileños que salieron debido al golpe militar de 
1964 (Norambuena, Palomera y López 2017), de los bolivianos que escaparían de la dictadura de Bánzer, y de algunos revolucionarios peruanos que salieron durante el gobierno militar de Perú.

Es significativo distinguir que el gobierno boliviano de Hugo Bánzer fue uno de los primeros después de Brasil donde se cometieron violaciones a los derechos humanos y se expulsó masivamente a su población. Estas expulsiones permitieron que Perú y Chile de la Unidad Popular se convirtieran, aunque fuera por un tiempo, en lugares de refugio para los bolivianos.

De fuerte componente intelectual, los primeros exiliados del banzerato optaron por acogerse a las garantías que países como Chile, Perú y, en menor medida Argentina, ofrecieron en los primeros años de la década de los setenta. La frontera compartida y los proyectos políticos que encabezaron tanto Juan Velasco Alvarado como Salvador Allende determinaron que un número importante de los expulsados optaran por la cercanía geográfica y la libertad para reconformar el trabajo opositor a la dictadura (Andújar 2010).

En 1976 la Comisión Interamericana solicitó a varios países de América que respondieran frente a denuncias referidas a violaciones de los derechos humanos, entre ellos a Bolivia. Este fue el único país del Cono Sur que no entregó la información requerida (CIDH 1976).

\section{Dictadura y doble refugio}

La segunda etapa de refugio en Chile concierne al periodo que cubre entre 1973 y 1975, y está limitada por la caída del gobierno del presidente Salvador Allende tras el golpe militar, el advenimiento pleno de la dictadura militar, y la consiguiente salida de los extranjeros refugiados y asilados en Chile.

En este periodo la enérgica represión significó la inmediata detención de muchos ciudadanos chilenos y extranjeros. La información que ha sido posible levantar gracias a la documentación proveniente de distintos repositorios muestra que, en ese momento, refugiados que habían buscado asilo en Chile se vieron afectados nuevamente, algunos detenidos por la dictadura, torturados o asesinados; otros, debieron asilarse en embajadas, o bien buscar la protección de organismos nacionales.

El 20 de septiembre de 1973, en una operación relámpago, el Alto Comisionado de las Naciones Unidas para los Refugiados (ACNUR) se asentó en Chile, presionando al gobierno de facto a responder a los requerimientos internacionales. Posteriormente, el 24 de septiembre del mismo año, siguiendo la misma línea de protección, se sumó CONAR, que, aunque tuvo en principio una autorización de tres meses, se había constituido "en el punto de partida de una acción que se prolongaría por mucho más tiempo" (FASIC 2016: 1). Junto con estos se requirió el apoyo de otros organismos internacionales como CIME. En 1974 este organismo se convirtió en el Comité Internacional de las Migraciones (CIM) y posteriormente en la Organización Internacional para las Migraciones (OIM)), demostrando rapidez frente a las múltiples peticiones de protección política: "Aproximadamente cinco mil personas, chilenos y extranjeros, se refugiaron en embajadas y en otros lugares de protección, o se pusieron al amparo de diversos organismos internacionales" (Timmermann 2007: 7). A partir de estas operaciones se comenzó a negociar con el régimen las condiciones de salida de los extranjeros y los posibles países de acogida para ellos.

En este marco de protección es reconocida también la importancia que tuvieron algunas representaciones diplomáticas en los primeros meses del golpe militar como fue la embajada sueca. En la residencia de su embajador Harald Edelstam y en la oficina comercial cubana que había quedado bajo la protección de Suecia, se albergó a decenas de personas entre las que se encontraban jóvenes suecos que habían trabajado como voluntarios en el gobierno de la Unidad Popular, pero también uruguayos, brasileños, bolivianos, cubanos, ecuatorianos, peruanos, argentinos y chilenos que se habían refugiado tras el golpe (Camacho 2006).

También constatamos que en este tiempo hubo situaciones que concitaron la atención internacional, como fue la repatriación de un grupo de refugiados bolivianos realizada por militares en los primeros días del golpe, quienes posteriormente fueron apresados en su país por la dictadura de Hugo Bánzer. Este hecho es reconocido como uno de los casos más dramáticos en tema de amparo internacional y de Derechos Humanos (CIDH 1974).

Durante este periodo la violencia de la dictadura tuvo su antítesis en la labor que cumplieron estos 
organismos que prontamente y con el apoyo de organizaciones nacionales, lograron ir en ayuda de los refugiados extranjeros. Uno de los principales desafíos y aciertos que tuvieron estas instancias de refugio fue la capacidad de recorrer nuevos caminos en la protección internacional, como fue la creación de los llamados refugios temporales. Hasta ese momento no existía en la normativa internacional esta modalidad de protección, sin embargo, el CONAR, con el apoyo de Naciones Unidas, logró instalar seis albergues para refugiados que obtuvieron el reconocimiento del gobierno militar de Chile. La existencia de estos albergues significó la protección de cientos de refugiados que recibieron amparo jurídico, pero también servicios básicos como alimentación y vestimenta (CIDH 1974).

Como fue dicho, el impacto que causó el golpe en Chile y la represión instalada provocó la rápida movilización de los organismos internaciones, es así que la Comisión Interamericana de Derechos Humanos, dependiente de la Organización de Naciones Unidas, envió a su Secretario General Luis Reque a visitar el país para recoger información acerca de estos acontecimientos. Entre el 12 y 17 de octubre de 1973 fueron visitados centros de detención y casas de refugio habilitadas especialmente para los extranjeros que se encontraban en Chile. Reque, el 21 de octubre de 1973 emitió un informe minucioso a la Comisión, donde señalaba que quedaban cerca de 150 personas en los centros de refugio, los que estaban protegidos por la bandera de las Naciones Unidas o la Cruz Roja (CIDH 1974). Al visitar una de estas casas, Luis Reque señaló en su informe que "En la tarde del día lunes 15 de octubre me trasladé en compañía del señor Samuel Nalegach Pons del Comité Nacional de Ayuda a los Refugiados y un funcionario de la CEPAL al Centro de Refugiados 'Padre Hurtado'. [...] Había cerca de 120 refugiados, la mayoría de los cuales eran brasileños, bolivianos y uruguayos" (CIDH 1974).

La Comisión Interamericana dio cuenta del arduo trabajo que realizaron el Comité Nacional y el Alto Comisionado indicando en detalle cómo se había ejecutado la operativa en torno al refugio. Lo primero que se señalaba es que se habían contratado trabajadores voluntarios que habían empadronado a los extranjeros que deseaban ayuda, luego habían contribuido a la búsqueda de extranjeros desaparecidos, organizando a la par un servicio de salud para las personas que ingresaran a los albergues, manteniendo y administrando estas seis casas de refugio.

El Comité Nacional solicitó los salvoconductos, mientras la oficina del Alto Comisionado desempeñó la labor de buscar países de refugio para las personas de varias nacionalidades que querían salir de Chile y que no podían volver a sus propios países por razón de situaciones políticas (CIDH 1974).

En ese nuevo contexto, Chile, que de acuerdo con las palabras del obispo luterano Frenz, había sido reconocido como una isla de refugio (2006), se enfrentaba a la expulsión de estos extranjeros que habían encontrado protección en este país. Existe consenso en reconocer que luego del golpe militar chileno, la problemática de los derechos humanos y expulsión masiva de población, pasó a transformarse en una preocupación a nivel regional e internacional.

Esta visibilidad internacional de las comunidades de exiliados y otras víctimas de violaciones a los derechos humanos fue resultado de la combinación, por un lado, de las acciones políticas de los desterrados y de organizaciones humanitarias y de solidaridad en los países de acogida y foros internacionales, y, por el otro, de la existencia de una opinión pública mundial (Ayala, Mazzei 2015: 6).

Posterior a la visita del secretario Reque, la Comisión reunida en Cali, Colombia, se dirigió al gobierno de Chile, comenzando un intercambio de memorándums entre ambas partes. En su primera nota la CIDH, el 24 de octubre de 1973, solicitaba al vicealmirante Ismael Huerta Díaz, ministro de Relaciones Exteriores de Chile, que se entregara información respecto de los detenidos, torturados, desaparecidos y asesinados que habían sido notificados por Luis Reque en su paso por Chile, entre ellos, un grupo de ciudadanos extranjeros (CIDH 1974).

Por su parte, el Ministerio de Relaciones Exteriores de entonces aceptó como mecanismo de salida de los extranjeros la entrega de documentos de salvoconductos para chilenos y extranjeros que estaban en protección de la normativa internacional, separando la condición o categoría de amparo que 
presentaron estos ciudadanos, entre asilados, refugiados, expulsados y debe abandonar. Asimismo, se consideró en esta clasificación a quienes no se les entregaba salvoconducto por su propia condición, sino que por ser parientes de aquellos que detentaban la calidad de protegidos: hijas, hijos, esposas, esposos, madres y padres (MINREL 1975).

De acuerdo con los salvoconductos entregados por el Ministerio de Relaciones Exteriores, habrían salido de Chile más de 8.500 personas entre 1973 y 1975, oficialmente reconocidas, de ellas un número significativo eran de origen latinoamericano (MINREL 1975).

Para los extranjeros que debieron ser reasentados en terceros países significó un doble refugio. Cerca de 2.900 salvoconductos regulares fueron entregados a extranjeros que al momento del golpe estaban previamente protegidos por la normativa internacional, asilados en misiones diplomáticas o se encontraban en protección del Alto Comisionado de las Naciones Unidas para los Refugiados ACNUR, que como ya fue señalado, los había cobijado en centros de refugios temporales.

Esta incómoda presencia de extranjeros refugiados y la percepción que se instaló en los militares acerca de ellos, podría ser una de las determinantes que a dos años de iniciada la dictadura militar se haya promovido la creación de la Ley de Extranjería, de carácter extremadamente restrictivo, debido al procedimiento de ingreso de extranjeros al país (Ley No 1094 de 1975).

Artículo $2^{\circ}$ - Para ingresar al territorio nacional los extranjeros deberán cumplir los requisitos que señala el presente decreto ley, y para residir en él deberán observar sus exigencias, condiciones y prohibiciones. Por decreto supremo podrá prohibirse el ingreso al país de determinados extranjeros por razones de interés o seguridad nacionales (Ministerio del Interior 1975).

Como se observa en este artículo, esta normativa buscaba la regulación del tipo de extranjeros que se permitirían en el país, postulados que se mantiene vigente hasta la actualidad.

\section{Bolivianos refugiados en Chile}

La información recabada en los salvoconductos entre 1973 y 1975, entregada por el Ministerio de
Relaciones Exteriores, señala que cerca de 529 ciudadanos bolivianos solicitaron protección en Chile durante el periodo de análisis.

Tabla 1. Tipo de salvoconducto de bolivianos en Chile 1973-1975.

\begin{tabular}{lc}
\hline Condición & Bolivia \\
\hline Asilados & 75 \\
Cortesía & 51 \\
Debe Abandonar & 30 \\
Expulsado & 93 \\
Refugiados & 280 \\
Total & 529 \\
\hline
\end{tabular}

Elaboración propia. Ministerio de Relaciones Exteriores 1973-1975. Archivo FASIC.

Como se ha señalado, la cercanía de Chile y la presencia del gobierno del presidente Salvador Allende fueron parte de las razones por la que encontramos el considerable número de 529 refugiados bolivianos en el territorio nacional.

Un breve periodo de tiempo bastó para que los bolivianos lograran estructurar una organización de exiliados en la capital chilena. Con excepción de la Ciudad de México, en Santiago un número importante de personas provenientes del país andino encontró cobijo en partidos políticos, organizaciones sociales y el gobierno de Salvador Allende (Andújar 2010).

Los guarismos nos indican que más del 90 por ciento de los que obtuvieron salvoconductos fueron en condición de asilado, refugiado, expulsados o debe abandonar. Asimismo, demuestran la mayor cuantía de los refugiados y expulsados. Esto explicaría la decidida presencia de las organizaciones de protección en el proceso de salida de estas personas; el CIME se preocupó de la situación de 93 expulsados, 75 asilados y de 51 ciudadanos que salieron por cortesía. A su vez, CONAR estuvo a cargo de la protección de todos aquellos que oficialmente fueron reconocidos como refugiados, gestionando sus salvoconductos y la sobrevivencia de los mismos.

Muchos de los refugiados encontraron en Chile un lugar donde pudieron volver a reorganizarse de acuerdo con la militancia que traían desde Bolivia, como fue el caso de los que pertenecieron al Movimiento de Izquierda Revolucionaria (MIR) y al Partido Socialista (PS); también creando 
otras instancias organizativas: "Desde Santiago el exilio se agrupó por filiación política y en una asociación más amplia de bolivianos denominada Frente Revolucionario Antimperialista (FRA)" (Andújar 2010).

Esta mayor presencia se refleja en diversos relatos que se relacionan con la detención, muerte y expulsión de bolivianos en manos de las fuerzas armadas y no así de peruanos, demostrando la diferencia política de ambos procesos y el impacto que provocó en las autoridades militares la existencia de bolivianos refugiados en el país. Como señalamos con anterioridad " $[\ldots]$ en los primeros días del golpe militar, un grupo de casi 315 bolivianos de Antofagasta fue relegado a Bolivia donde inmediatamente fue apresado" (Frenz 2006: 146). Según el informe de Frenz, en principio los militares habían señalado esta situación como un error, pero posteriormente argumentarían que estas personas habían vuelto por su propia voluntad a su país.

La Comisión Interamericana en su informe concerniente a las violaciones a los derechos humanos en Chile, aumentó esta cifra de deportados y entregó más detalles, señalando que en lo que concernía con los refugiados bolivanos, 350 habían sido "repatriados del Norte de Chile debido a lista de refugiados suministrada por el cónsul boliviano a las autoridades chilenas y que muchos de los repatriados se encuentran en los campos de concentración de Uyuni" (CIDH 1974).

Acerca de los extranjeros detenidos, un antecedente significativo es el que se manejó respecto de los prisioneros del Estadio Nacional, lugar a donde se llevó a un considerable grupo de prisioneros chilenos y refugiados extranjeros. Según la Comisión Nacional pertinente a prisión política y tortura, "el día 22 de septiembre, la Cruz Roja había identificado la presencia de alrededor de 7.000 prisioneros políticos, entre los cuales había entre 200 y 300 extranjeros de diversas nacionalidades (CIDH 1974: 524). En esta nómina se encontraban ciudadanos refugiados bolivianos. Por su parte, el Secretario Ejecutivo enviado por la CIDH, Luis Reque, señalaba que las autoridades le habían informado de la existencia de " 250 extranjeros. De estos, se comprometían a dejar en libertad a 120 , y se concluía en el informe que "la mayoría eran brasileños, uruguayos y bolivianos" (CIDH 1974).

El Estadio Nacional y otros recintos fueron lugares de confinamiento, tortura, fusilamiento y desaparición. La CIDH pidió al gobierno de Chile clarificar la situación de personas que luego de encontrarse detenidas habían sido torturadas, estaban desaparecidas o bien habían muerto.

Uno de los refugiados bolivianos detenidos en el Estadio Nacional fue Luciano Durán Böger, poeta y escritor. Luis Reque informó que en su visita a Chile había sostenido conversaciones con un grupo de extranjeros latinoamericanos por su detención y la situación en que se hallaban. Acerca de este encuentro señalaba que el escritor boliviano Luciano Durán había manifestado que "fue detenido el 24 de septiembre, en las puertas de la Embajada de México; que había llegado al país el 23 de diciembre de 1971; que había recibido buen trato y que no deseaba regresar a Bolivia. Expresó su preferencia por Francia o México" (CIDH 1974).

Este literato es recordado por un célebre poema que escribió en un pañuelo estando detenido junto con 18 bolivianos en el camarín $\mathrm{N}^{\circ} 3$ del Estadio Nacional. El poema Adiós es uno de los registros históricos que evidencia la violencia política en el periodo de estudio y en la actualidad se encuentra en el Museo de la Memoria de Chile (Durán, L.). De acuerdo con el testimonio del chileno José Santiago Cavieres Korn, momentos antes de escribir el poema les habían comunicado a los bolivianos detenidos que serían reubicados. Frente a esta situación, el escritor boliviano, asumiendo que podían ser asesinados, solicitó un papel para escribir un poema. Cavieres relató que en su reemplazo, pasó su pañuelo a Durán, dejando plasmada la "hermandad de bolivianos y chilenos a quienes les tocó sufrir la violencia política y la tortura" (Compartiendo Cultura 2013).

Este poema representó para muchos el ejemplo de un periodo de fraternidad y solidaridad al interior de América Latina.

En los salvoconductos entregados por el Ministerio solo se constata la expulsión de Durán Böger y que fue el CIME quien se encargó de su salida. En este caso no se registró en los documentos lugar de destino (MINREL 1975).

En esta misma línea, el secretario de la CIDH destacó la conversación con otro refugiado boliviano, Ignacio Miashiro, quien había sido detenido el día 14 de septiembre. Miashiro, fue un militante maoísta que en Bolivia había sido conocido por el asalto al Panóptico Nacional, llegando a Chile como refugiado en 1971. Reque, en su informe destacó que Miashiro le había señalado que desconocía "las causas de su detención y los cargos que existen 


\begin{tabular}{|l|l|}
\hline "Adiós \\
Ya nos vamos \\
¿Volveremos \\
al punto de partida \\
de un 11 de septiembre? iNo! \\
Ya nos vamos \\
hermanos chilenos \\
que nadie \\
siembre alegrías \\
sobre la sangre caliente \\
de las calles de Santiago \\
Ya nos vamos \\
de aquí \\
de este encerrón colectivo; \\
dentro \\
de nuestro corazón boliviano \\
dos manos \\
se dan la mano \\
y el hambre \\
hecho dolor abrió una zanja profunda; \\
en nuestros pechos hermanos \\
se dan \\
un abrazo de adiós, \\
Chilenos y Bolivianos"
\end{tabular}

Figura 1. Pañuelo de tela en el que Luciano Durán, boliviano, escribió el poema "Adiós", y alrededor de este firmaron los 80 prisioneros del camarín número tres del Estadio Nacional (Biblioteca digital. Museo de la Memoria).

en su contra y que no deseaba regresar a Bolivia" (CIDH 1974). Claramente, con la dictadura de Bánzer era difícil que quisiera volver a su país. De acuerdo con los salvoconductos entregados por el gobierno, en Chile fue protegido por el CIME, siendo expulsado por las autoridades, con destino a Suecia (MINREL 1975).

Otro caso de refugiado boliviano en el país fue el de Augusto Siles, quien señaló sobre su paso por Chile que se había venido a principios de 1973 para apoyar el proceso revolucionario, y continuar con la actividad política vinculada al Partido Socialista. En entrevista realizada en Cochabamba, en mayo de 2007 por Eusebio Andújar, señaló que sentía en Chile "una identificación total con el proceso que vivía en ese momento con la conducción de Allende [...] estábamos organizando siempre la forma de avanzar, de apoyar en la formación en los sindicatos" (Andújar 2010). Siles fue protegido como refugiado por el Comité Nacional para Ayuda a los Refugiados (CONAR) y sacado del país con dirección a Suecia (MINREL 1975). En la misma condición se encontraba el boliviano Pablo Ramos Sánchez, uno de los fundadores del Movimiento de
Izquierda Revolucionaria boliviano (MIR), que se trasladó a Chile, luego de ser exiliado en México durante el gobierno de Bánzer. En una entrevista realizada en La Paz, el 2007, señaló que tras una breve residencia en México donde trabajó en la Universidad, "También ejercí la docencia en Chile, hasta el golpe de Pinochet, y tuve que volver de nuevo a México y luego salir a Santo Domingo" (Ramos 2012). En Chile obtuvo la calidad de refugiado, siendo protegido por CONAR, quienes se encargaron de su salida a México (MINREL 1975).

La significativa presencia de bolivianos refugiados en Chile quedó de manifiesto en uno de los memorandos enviados por la CIDH al vicealmirante Huerta, ministro de Relaciones Exteriores, donde se insistía en conseguir información acerca de un grupo de extranjeros que aparecieron mencionados en la nómina que el representante de la ONU había solicitado con anterioridad acerca de los derechos humanos.

Que el doctor Jorge Ríos Dalens (boliviano), que tenía sus papeles en orden, con residencia definitiva, fue detenido y apareció 
muerto; Que Felipe Inigas (boliviano), fue detenido y torturado; Que Antonio Moreno (boliviano), fue detenido, acusado de francotirador, y ha desaparecido; Que Gualberto Lizarraga (boliviano), fue torturado y tiene un brazo fracturado; Que Luis Vélez (boliviano), fue detenido y ha desaparecido; Que Carlos Toranzos (boliviano), fue detenido y ha desaparecido (CIDH 1974).

La respuesta del ministro de Relaciones Exteriores de Chile se dio el 27 de marzo de 1974. En su carta, el vicealmirante Huerta señalaba que de las 16 personas que la Comisión había solicitado información por estar desaparecidas no se tenía información de todos, porque la mayoría habían salido del Chile, "13 de ellas hicieron abandono del territorio de la República, sea voluntariamente o expulsados del país" (CIDH 1974). Continuaba señalando que estas personas habían sido acusados de atentar contra la Seguridad Nacional y alterar el orden del país. Entre los expulsados se contaban los bolivianos Antonio Moreno, Luis Vélez y Carlos Toranzos (CIDH 1974). En el caso de Luis Vélez fue acogido por el CIME en condición de expulsado, Carlos Toranzo Roca se asiló en la embajada de México, para salir con rumbo al mismo país de acogida. Por su parte, Antonio Moreno fue expulsado y protegido por el CIME (MINREL 1975).

Años más tarde, Moreno señalaba que había caído preso en Chile con otros ciudadanos bolivianos, René Higueras y Edgar Cadima. En su testimonio recuerda que con Cadima habían convenido proteger a sus hijos y padres si alguno de ellos moría, no obstante, días después, un militar les informó que tenían suerte porque había arribado al Estadio una Comisión de Naciones Unidas que se los llevaría. "Poco después fueron trasladados al refugio del convento Padre Hurtado. Y semanas más tarde los trasladaron a París para luego distribuirlos en diversas capitales europeas como asilados" (Sagárnaga 2016).

Respecto de la muerte de Jorge Ríos Dalens, el mismo informe del vicealmirante señalaba que se carecía de "información oficial y se investigarían las causas que produjeron su deceso" (CIDH 1974). Militante de un partido de izquierda boliviano, llegó a Chile luego del golpe de Hugo Bánzer, fue estudiante de la Facultad Latinoamericana de Ciencias Sociales (FLACSO) y fue detenido por militares en su domicilio el 13 de septiembre de 1973, siendo encontrado su cuerpo el 18 de septiembre en el
Instituto Médico Legal. El certificado médico de defunción del Instituto Médico indicaba que Ríos había muerto "por múltiples heridas de bala craneoencefálica, cervical, torácicas, abdominal y de extremidades con salida de proyectiles" (Ríos 1973).

Otro de los bolivianos presente al momento del golpe militar chileno fue René Zavaleta Mercado, intelectual y político que llegó a Chile en 1971, luego del golpe de Estado en Bolivia. En Chile se destacó por su trabajo en el Centro de Estudios sobre la Realidad Nacional (CEREN) de la Universidad Católica de Chile.

El CEREN funcionó en el marco de la Universidad Católica de Chile como una de las usinas intelectuales más lúcidas y productivas durante el proceso de la Unidad Popular (1970-1973). Los investigadores del CEREN, así como los que logró convocar [...] se habían trazado un proyecto ambicioso: pensar las condiciones económicas, sociales, políticas y culturales de una transformación revolucionaria en Chile en el marco de un gobierno popular (Tarcus 2007).

Zavaleta fue conocido como uno de los intelectuales latinoamericanos prestigiosos que pasó por Chile, "la presencia de Zavaleta en nuestro país estuvo sellada por una tarea intelectual que, si de un lado es visto como de encuentro definitivo de su pensamiento con el marxismo, de otro, importaría una más elocuente latinoamericanización del mismo" (Loyola 2014).

Posterior a su salida del país, buscó asilo en México junto con otros de sus compatriotas, destacándose en ese país en el ámbito educativo. Si bien en Chile fue donde elaboró su teoría acerca del poder dual, su capacidad de trabajo intelectual habría continuado en su nuevo exilio en México, resultando "notorio el fortalecimiento de la red universitaria de bolivianos con la llegada de intelectuales como René Zavaleta Mercado luego del golpe de Estado en Chile y de Marcelo Quiroga hacia 1975 (Andújar 2013).

\section{Reflexiones finales}

A modo de síntesis, constatamos que el refugio y doble refugio en Chile fue la expresión de una convergencia de factores internos y externos. 
La atracción política generada por el gobierno de Salvador Allende coincidió con la diáspora de cientos de ciudadanos en el marco de gobiernos militares inspirados en la Doctrina de Seguridad Nacional, como fue el caso de Bolivia.

El asilo y refugio otorgado por el gobierno de la Unidad Popular a numerosos latinoamericanos expulsados por los gobiernos dictatoriales instalados en el Cono Sur de América, permitió que en Chile se radicara una amplia comunidad de mujeres y hombres que habían sido expulsados de sus países o bien habían solicitado asilo encontrándose en calidad de refugiados.

Las diferencias políticas y el impacto del exilio o salida de su país de estos ciudadanos bolivianos, generaron en Chile una política específica para hacerse cargo del refugio, ampliándose estas medidas y alcanzando importantes magnitudes como la ratificación del Convenio de 1951 y del Protocolo de 1967.

Sin embargo, este proceso de asilo y refugio otorgado por el gobierno de la Unidad Popular a latinoamericanos y bolivianos en particular, sufrió un duro revés con el golpe militar de Augusto Pinochet, produciéndose la persecución, prisión política y expulsión de muchos de ellos.

Respecto de la represión política en este periodo dictatorial, es significativo reconocer que, si bien se produjo la expulsión inmediata de un grupo de habitantes bolivianos en el norte del país y el encarcelamiento, tortura, desaparición y muerte de otros de sus connacionales, los avances jurídicos y la generación de una política de amparo realizada por el gobierno del presidente Allende junto con la rápida y efectiva colaboración de organismos como ACNUR, CIME y CONAR, condicionaron la colaboración del gobierno autoritario, permitiendo la protección y reubicación de la mayoría de los bolivianos refugiados y asilados en el territorio chileno.

En este proceso, el asilo diplomático en las embajadas de países acreditados y casas de refugio de ACNUR permitieron la protección y reubicación de ciuadadanos bolivianos que se encontraban en peligro frente al gobierno militar.

La dictadura debió responder periódicamente ante las acusaciones de detenciones ilegales, torturas, desapariciones y deportaciones de ciudadanos extranjeros. La acción de salvataje de los refugiados, entre los que se encontraban 529 ciudadanos bolivianos registrados, no impidió que estos y otros refugiados fueran objeto de violaciones a sus derechos humanos incluido el derecho a la vida tal cual hemos relevado en los testimonios y documentos pesquisados.

La protección de estos refugiados fue posible gracias a la acción de la comunidad internacional y a la construcción de redes de protección y centros de acogida, que les permitió estar a salvo de la acción de los organismos represivos o de ser devueltos a los gobiernos de los que habían debido escapar. Intelectuales, políticos, académicos y trabajadores hombres y mujeres dejaron una huella inscrita en la memoria dolorosa de los oscuros años de las dictaduras latinoamericanas que, en el caso chileno, se expresó significativamente en la figura del doble refugio.

\section{Referencias Citadas}

Alto Comisionado de las Naciones Unidas para los Refugiados. 2005 Memoria del Vigésimo Aniversario de la Declaración de Cartagena sobre los Refugiados 1984-2004. San José, C.R. Editorama.

Andújar, E.

2010 "Redes sociales del exilio andino: consideraciones en torno a la presencia de los bolivianos en Perú y Chile durante los años setenta del siglo XX". Revista Pacarina del sur. 3: s/p. http://pacarinadelsur.com/ediciones/numero-3 (9 mayo 2017).

Andújar, E.

2013 "El exilio boliviano en México: prácticas intelectuales y redes sociales". Revista de la Biblioteca y Archivo Histórico de la Asamblea Legislativa Plurinacional 7/(27):21-35. http://www.revistasbolivianas.org.bo/scielo.php?pid=S1997 44852013000400004\&script=sci_arttext (06 marzo 2017).
Angell, A.

1997 "La izquierda en América Latina desde c. 1920". En Historia de América Latina, coordinado por Leslie Bethell, Vol. 12, pp. 73-131. Crítica, Barcelona.

Ayala, M. y Mazzei, D.

2015 "Los exilios políticos del Cono Sur de América Latina: temas, enfoques y perspectivas". En Historia. Voces y Memoria. Buenos Aires 8:5-12.

Brahm, E. y Montes, J.

2012 "El Frente Popular y la Inmigarción judía a Chile: De la apertura al cierre total". Revista Chilena de Derecho, Vol. $39 \mathrm{~N}^{\circ}$ 3, pp. 909-917.

De la Peña, G.

1997 "Las movilizaciones rurales en América Latina desde c. 1920". En Historia de América Latina, coordinado por Leslie Bethell, Vol. 12, pp. 193-280. Crítica, Barcelona. 
Cajías, F.

2013 "Narrativa general del periodo (1930-1990)". En Historia de América Andina. Editado por Mauricio Archila, Vol. 7 , pp. 119-176. Editorial Ecuador.

Camacho, F.

2006 "Los asilados de las Embajadas de Europa Occidental en Chile tras el golpe militar y sus consecuencias diplomáticas: El caso de Suecia". European Review of Latin American and Caribbean Studies. 81: 21-41. http://www.cedla.uva. n1/50_publications/pdf/revista/81RevistaEuropea/81Cama cho-ISSN-0924-0608.pdf (20 mayo 2017).

Comisión Interamericana de Derechos Humanos (CIDH).

1976 Informe anual de la Comisión Interamericana de Derechos Humanos 1975. Organización de los Estados Americanos.

Comisión Interamericana de Derechos Humanos (CIDH). 1974 Informe sobre la situación de los Derechos Humanos en Chile [Consultado el: 15/04/2017]. Disponible en: http:// www.cidh.org/countryrep/chile74sp/Indice.htm

Comisión Nacional sobre prisión política y tortura.

2003 Informe. Biblioteca del Congreso Nacional.

Compartiendo Cultura.

2013 El poema del pañuelo del Estadio Nacional. Museo de la Memoria [Consultado el: 16/04/2017]. Disponible en: https://jduranboger.wordpress.com/2013/04/17/ el-poema-del-panuelo-del-estadio-nacional/

Del Pozo, J.

2009 Historia de América Latina y del Caribe: desde la Independencia hasta hoy. LOM ediciones, Santiago de Chile.

Departamento de Extranjería y Migración (DEM).

1976 Decreto $N^{o} 57$. Ministerio del Interior. Santiago, 15 de enero de 1976.

Durán Böger, L.

1973 "Estadio N. de Santiago, Camerín No 3 - 9-X-1973". Museo de la Memoria y los Derechos Humanos [Consultado el: 15/08/2017]. Disponible en: http://archivomuseodelamemoria.cl/index.php/68162;isad

Esponda, J.

2004 "La tradición latinoamericana de asilo y la protección internacional de los refugiados". En El asilo y la protección internacional de los refugiados en América Latina: Análisis crítico del dualismo "asilo-refugio" a la luz del Derecho Internacional de los Derechos Humanos. Coordinador Franco, L. pp. 77-125. ACNUR, Editorama; San José, Costa Rica.

Frenz, $\mathrm{H}$.

2006 Mi vida chilena: solidaridad con los oprimidos. LOM ediciones. Santiago de Chile.

Fundación de Ayuda Social de las Iglesias Cristianas (FASIC). 2016 El 24 de septiembre de 1973, comenzó a funcionar el CONAR [Consultado el: 20/08/2017]. Disponible en: http://fasic.cl/wp/2016/09/el-24-de-septiembre-de-1973 -comienza-a-funcional-el-conar/

Garcés, M. y Nicholls, N.

2005 Para una Historia de los derechos Humanos en Chile. Historia Institucional de la Fundación de Ayuda Social de las Iglesias Cristianas FASIC 1975-1991. LOM Ediciones, Chile.

Grinsvall, S. y Lora, M.

2012 "La Experiencia del exilio político y sus consecuencias en la subjetividad”. En Аjayu. Órgano de Difusión
Científica del Departamento de Psicología de la Universidad Católica Boliviana, San Pablo, 10/2: 172-185 [Consultado el: 25/05/2017]. Disponible en: http://www.redalyc.org/ pdf/4615/461545462004.pdf

Hernández, J.

2015 "Triunfa el Golpe de Bánzer en Bolivia”. En La izquierda (23/08/2015). Cultura [Consultado el: 06/04/2017]. Disponible en: https://www.laizquierdadiario.com/ Triunfa-el-golpe-de-Banzer-en-Bolivia?id_rubrique $=5443$ López, M.

2013 "Estado y democracia en los países andinos. Entre 1930 y 1990: Una aproximación". En Mauricio Archila Historia de América Andina. Vol. 7, pp. 177-228. Editorial Ecuador.

Loyola, M.

2014 René Zavaleta Mercado y la "Unidad Popular chilena: los avatares de la dualidad de poderes". En Red Seca, Revista de Actualidad Política, Social y Cultural [Consultado el: 07/05/2017]. Disponible en: http://www.redseca.cl/ rene-zavaleta-mercado-y-la-unidad-popular-chilena-losavatares-de-la-dualidad-de-poderes/

Melander, G.

1981 Refugees and International Cooperation. Center for migration studies of New York, Inc. The international Migration Review, 15-1/2: 35-41.

Mesa, J.; Gisbert, T. y Mesa, C.

2003 Historia de Bolivia. Editorial Gisbert.

Ministerio del Interior.

1975 Decreto de Ley 1094, Establece normas sobre extranjeros en Chile. Fecha Publicación: 19-07-1975.

Ministerio de Relaciones Exteriores (MINREL).

1975 Relación de Salvoconductos otorgados a personas asiladas y refugiadas y en otras condiciones a partir del 11 de Septiembre de 1973. Archivo FASIC.

Norambuena, C.

2008 "El exilio de las dos orillas. España del 39 y Chile 73. Producción y aportes culturales". En Migraciones, integración e identidad. Miradas de Idas y de Vueltas, Santiago de Chile. Edit. Sud-Americana.

Norambuena, $\mathrm{C}$.

2000 "Exilio y retorno. Chile 1973-1994". En Memoria para un nuevo siglo: Chile, miradas a la segunda mitad del siglo XX. Garcés, M. [et al.]. pp. 173-187. LOM Ediciones, Chile.

Norambuena, C.; Palomera, A. y López, A.

2017 Brasileños en Chile durante la dictadura militar. Doble refugio 1973-1974 (en referato).

Organización de Naciones Unidas (ONU).

1951 Convención sobre el Estatuto de los Refugiados. Ginebra, Suiza [Consultado el: 29/04/2017]. Disponible en: http:// www.acnur.org/fileadmin/scripts/doc.php?file=fileadmin/ Documentos/BDL/2001/0005.

Organización de Naciones Unidas (ONU).

1967 Protocolo sobre el Estatuto de los Refugiados. Nueva York, Estados Unidos [Consultado el: 29/05/2017]. Disponible en: http://www.acnur.org/fileadmin/scripts/doc. php?file=fileadmin/Documentos/BDL/2001/0003

Paredes, A.

2004 “La Operación Cóndor y la guerra fría". Revista Universum, 19/1: 122-137 [Consultado el: 09/06/2017]. Disponible en: http://www.scielo.cl/scielo.php?script=sci_ar ttext\&pid=S0718-23762004000100007 
Péres, J.

2003 LXXV años. Regulación y supervisión financiera en Bolivia, 1928-1982. Superintendencia de bancos y entidades financieras. La Paz, Bolivia.

Ramos, P.

2012 De las aulas a la literatura. La Razón, animal político [Consultado el: 14/06/2017]. Disponible en: http://www. larazon.com/index.php?_url=/suplementos/animal_politico/ aulasliteratura_0_1691830937.html

Ríos, J.

1973 Víctimas, Museo de la Memoria [Consultado el: 27/06/2017]. Disponible en: https://interactivos.museodelamemoria.cl/victimas/?p=1357

Sagárnaga, R. Antonio Moreno

2016 "Una vida entre la resistencia y las guerrillas". En El País, 4/01/2016 [Consultado el: 28/05/2017]. Disponible en:http://www.elpaisonline.com/ index.php/2013-01-15-14-16-26/local/item/200318 antonio-moreno-una-vida-entre-la-resistencia-y-las-guerrillas Sznajder, M. y Roniger, L.

2013 La política del destierro y el exilio en América Latina. México: Fondo de Cultura Económica.
Tarcus, $\mathrm{H}$.

2007 Introducción. En $O S A L$, Año VIII, Nº 22, septiembre. Buenos Aires. CLACSO [Consultado el: 22/05/2017]. Disponible en: http://bibliotecavirtual.clacso.org.ar/ar/ libros/osal/osal22/APC22Tarcus.pdf

Timmermann, F.

2007 "Su Más Amargo Cáliz, El Cardenal Silva Henríquez Frente a la Violencia del Régimen Cívico-Militar. Chile, 1973-1975". Revista de Historia y Geografía, No 21. Universidad Católica Silva Henríquez.

Victoriano, F.

2010 "Estado, golpes de Estado y militarización en América Latina: una reflexión histórico política”. En Revista Argumentos UAM-X México, 23/64: 175-193 [Consultado el: 05/05/2017]. Disponible en: http://www.scielo.org.mx/scielo. php?script=sci_arttext\&pid=S018757952010000300008 Wilkinson, R.

2015 El asilo no tiene precio. Vale tanto como la propia vida. Alto Comisionado de las Naciones Unidas para los Refugiados [Consultado el: 17/06/2017]. Disponible en: http://www.acnur.org/el-acnur/historia-del-acnur/ el-asilo-no-tiene-precio-vale-tanto-como-la-propia-vida/ 